\title{
Strengthening of Calcium Phosphate Cement by Compounding Calcium Carbonate Whiskers
}

\author{
Masayuki KON ${ }^{1}$, Luciana M. HIRAKATA², Youji MIYAMOTO ${ }^{3}$, Hidemitsu KASAHARA ${ }^{4}$ \\ and Kenzo ASAOKA ${ }^{1}$ \\ ${ }^{1}$ Department of Biomaterials and Bioengineering, Course of Maxillo-Oral and Regenerative Medicine, Institute of Health \\ Biosciences, Tokushima University Graduate School, 3-18-15 Kuramoto, Tokushima 770-8504, Japan \\ ${ }^{2}$ Department of Prosthodontics, Faculty of Odontology, Pontifical Catholic University of Rio Grande do Sul, Porto Alegre, \\ Rio Grande do Sul 90.050-180, Brazil \\ ${ }^{3}$ Division of Dentistry and Oral Surgery, School of medicine, Akita University, 1-1-1 Hondou, Akita 010-8543, Japan \\ ${ }^{4}$ Department of Research and Development, Maruo Calcium Co., 1455 Nishioka, Uozumi-cho, Akashi 674-0084, Japan \\ Corresponding author, E-mail:massy@dent.tokushima-u.ac.jp
}

Received January 19, 2005/Accepted February 14, 2005

\begin{abstract}
The purpose of this study was to investigate how aragonite (calcium carbonate) whiskers influenced the strengthening and carbonating of $\alpha$-tricalcium phosphate ( $\alpha$-TCP) based calcium phosphate cement. Aragonite whiskers of $0.95 \mu \mathrm{m}$ width with an aspect ratio of 6.6 were prepared. The cement powder, $\alpha$-TCP containing 0-50 mass \% aragonite whisker, was mixed with $0.6 \mathrm{~mol} / \mathrm{L} \mathrm{NaH} \mathrm{PO}_{4}$ solution and incubated at $37^{\circ} \mathrm{C}$ and $100 \%$ relative humidity. Diametral tensile strength (DTS) value increased significantly when appropriate amount of aragonaite whiskers was added. For example, DTS value of set cement containing 20 mass \% aragonite whisker was $5.8 \pm 0.5 \mathrm{MPa}$, whereas DTS value of set cement containing no whiskers was $1.3 \pm 0.2 \mathrm{MPa}$ after 1-week incubation. SEM observation revealed that the shape of the whiskers and the densification of the structure could have contributed to the strengthening of the set cement. Moreover, FTIR spectra implied that a bonelike carbonated apatite was precipitated in the cement. The results obtained in the present study revealed that the shape as well as any slight dissolution of aragonite whiskers could contribute to improving the properties of $\alpha$-TCP based calcium phosphate cement.
\end{abstract}

Key words: Calcium carbonate whisker, Calcium phosphate cement, Strength

\section{INTRODUCTION}

Calcium phosphate cements are known to possess excellent biocompatibility and bioactivity. Thus, they are widely used in medical and dental clinics as a bone-filling (or bone-replacing) material as well as a root sealer. Calcium phosphate cements which have been commercialized and studied can be roughly classified into two types based on the composition of cement powder. For type I, the cement powder consists of a mixture of tetracalcium phosphate (TTCP) and dicalcium phosphate (DCPA or DCPD $)^{1-4)}$. For type II, the cement powder is $\alpha$ tricalcium phosphate $(\alpha-\mathrm{TCP})^{4-14)}$. Both types of cement powder are hardened by mixing with water or aqueous solution, and crystal phases in the set cement finally transform to hydroxyapatite (HAP). Type I cement has a dense structure after setting because of the precipitation of small needle-like HAP crystals $^{1,2)}$. In contrast, dense structure cannot be obtained in type II cement consisting of only $\alpha$-TCP powder because of the precipitation of plate-like HAP crystals - owing to the formation of octacalcium phosphate $(\mathrm{OCP})$ as an intermediate ${ }^{15)}$. Due to the spaces between plate-like crystals, the strength of type II cement is lower than that of type I cement. Therefore, strength of type II cement must be improved to satisfy the stringent criteria of medical and dental applications.

One of the methods to improve the mechanical properties of a material is to add glass fibers and whiskers. In particular, glass fibers found many applications in the strengthening of plastic materials, and fiber glass reinforced plastics (FRP) are a typical example of the utilization of glass fiber. In addition, FRP has been investigated for its application as a medical or dental material (or even as a device) ${ }^{16-20)}$. We also reported that a conventional glass-ionomer cement could be strengthened by compounding short fibers with $\mathrm{CaO}-\mathrm{P}_{2} \mathrm{O}_{5}-\mathrm{SiO}_{2}-\mathrm{Al}_{2} \mathrm{O}_{3}$ glass, which was similar to the glass powder of the cement ${ }^{21)}$. There are two reasons why this strengthening could be achieved. First, it is because of the anisotropy in short glass fiber shape, second, it is because of reactivity (bonding) between the mixing liquid (or cement matrix) and the short glass fibers. This research implies that bonding between dispersing fiber particles and the weak matrix is very important - such as a silane coupling treatment of the dispersing fillers in composite resin.

We would like to propose calcium carbonate $\left(\mathrm{CaCO}_{3}\right)$ whiskers - which possess a particular aspect ratio (length/width) - to function as a reinforcing agent of calcium phosphate cement. Calcium 
carbonate is roughly classified into two crystal types: calcite of high temperature type and aragonite of low temperature type. The solubility of aragonite is slightly higher than that of calcite. Calcite, a typical calcium carbonate, is employed as one of the mixed powder constituents for calcium phosphate cement to the intent of regulating the reaction ${ }^{22)}$. Moreover, carbonate ion formed by a slight dissolution of calcium carbonate is expected to elicit carbonated apatite precipitation in the set calcium phosphate cement.

The purpose of this study was to investigate the effects of added aragonite whiskers on the reinforcement of calcium phosphate cement and on the precipitation of carbonated apatite.

\section{MATERIALS AND METHODS}

Preparation of whisker-containing cements

Original aragonite whiskers (Maruo Calcium Co., Akashi, Japan) used in this study were approximately $30 \mu \mathrm{m}$ in length and $0.95 \pm 0.15 \mu \mathrm{m}$ in width, as shown in Fig. 1. The whiskers were crushed with an alumina mortar grinder (ANM-1000, Nittokagaku Co., Japan) and sieved so that the length became 6.3 $\pm 1.7 \mu \mathrm{m}$. The mean aspect ratio (length/width) of these whiskers was 6.6. Moreover, aspect ratios of approximately 1.0 and 20 were used for investigating the effect of whisker shape on reinforcement.

As a base powder for calcium phosphate cements containing aragonite whiskers, $\alpha$-TCP was prepared from a mixed powder consisting of calcium carbonate $\left(\mathrm{CaCO}_{3}\right)$ and dicalcium phosphate dihydrate (DCPD; $\mathrm{CaHPO}_{4} \cdot 2 \mathrm{H}_{2} \mathrm{O}$ ) with a $\mathrm{Ca} / \mathrm{P}$ ratio of $1.5^{15,23)}$. The mixed powder was heated at $1400^{\circ} \mathrm{C}$ for five hours, then quenched in air to prevent transformation to $\beta$-TCP. The $\alpha$-TCP thus produced was crushed into

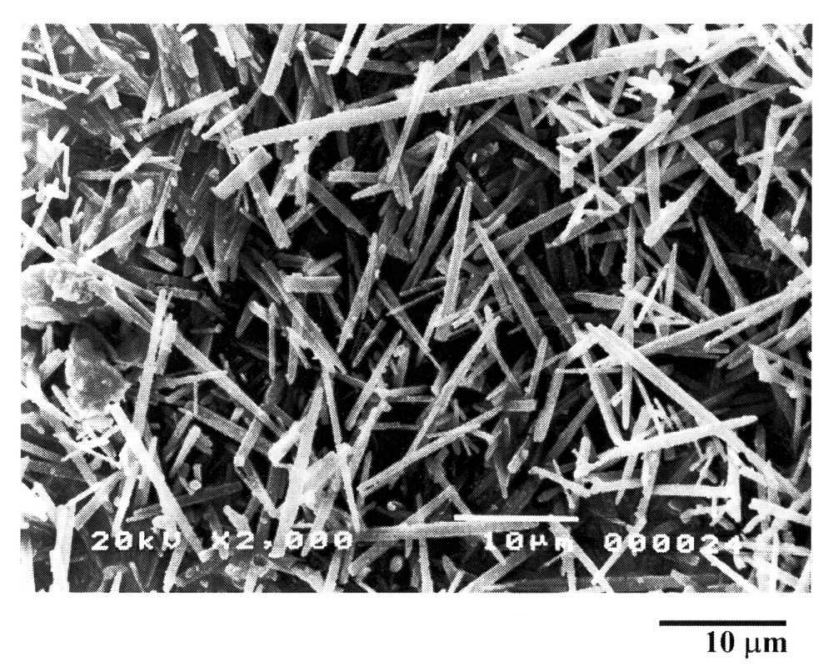

Fig. 1 Micrograph of aragonite $\left(\mathrm{CaCO}_{3}\right)$ whiskers used in this study and observed by scanning electron microscopy (SEM). a fine powder of approximately $2 \mu \mathrm{m}$ in diameter by a ball mill using an alumina ceramic cell (P-7 Planetary Micro Pulverizer, Fritsch Co., Idar Obertein, Germany). The powders for cement were prepared by mixing the $\alpha$-TCP powder and the whiskers. The whisker contents in the mixed powder were 0 (A), 10 (B), 20 (C), 30, and 50 mass\%. For the cement liquid, $0.3-1.2 \mathrm{~mol} / \mathrm{L}$ sodium dihydrogen phosphate $\left(\mathrm{NaH}_{2} \mathrm{PO}_{4}\right)$ solution was prepared ${ }^{15,23)}$. To combine the powder and liquid phases, all cement powders were mixed with the solution at a powder/liquid $(\mathrm{P} /$ $\mathrm{L}$ ) ratio of 3.0. Utensils used for the mixing were a glass plate and a stainless steel spatula for dental zinc phosphate cement. After mixing, the cement paste was placed in a plastic mold $(6 \mathrm{~mm}$ diameter $\times 3 \mathrm{~mm}$ height), and the mold kept in an incubator at a temperature of $37^{\circ} \mathrm{C}$ and relative humidity of approximately $100 \%$.

Setting time, strength, and analysis of cements The setting time of cements was measured using a Vicat needle according to the guidelines of the Japanese Industrial Standard, JIS T6607 (correspondence: ISO 7489), for dental glass polyalkenoate cement. Measurement was carried out at room temperature (approximately $20^{\circ} \mathrm{C}$ ).

The strength of set cements was evaluated by wet diametral tensile strength (DTS) test ${ }^{13-15}$. After storing in an incubator for 24 hours or one week, the wet DTS of disk specimens $(6 \mathrm{~mm} \phi \times 3$ $\mathrm{mm}$ ) for each condition was estimated using a Universal Testing Machine (Autograph AGS-500A, Shimadzu Co., Kyoto, Japan) with a cross-head speed of $1.0 \mathrm{~mm} / \mathrm{min}$. The mean value and its standard deviation for DTS were obtained from seven measurements. The data were statistically analyzed - by one-factor analysis of variance (ANOVA) and Fisher's PLSD post-hoc multiple comparison procedure - to determine the effect of adding whiskers on the strengthening of calcium phosphate cement.

The crystal phases in set cement were analyzed with a powder X-ray diffractometer system (XRD; ADG-301, Toshiba Co., Tokyo, Japan). The XRD conditions were $\mathrm{Ni}$ monochromatized $\mathrm{CuK} \alpha=$ radiation $(\lambda=0.154 \mathrm{~nm})$ generated at $30 \mathrm{kV}$ and $16 \mathrm{~mA}$. Specimens for XRD were prepared by crushing with an agate mortar. The microstructures on/in the set cement were observed by a scanning electron microscope (SEM; JSM-5600LV, JEOL, Tokyo, Japan). For SEM observation, the set cement was sputtered with gold. A Fourier transform infrared spectrometer (FTIR; FTS-40, Bio-Rad, Hercules, CA, USA) was used to confirm the presence of carbonate radical in the set cement. Specimens for FTIR were prepared by mixing with potassium bromide $(\mathrm{KBr})$ powder. 


\section{RESULTS}

Table 1 shows the setting time of calcium phosphate cements containing 0-20 mass\% aragonite whiskers with mean aspect ratio of 6.6 . When $0.6 \mathrm{~mol} / \mathrm{L}$ $\mathrm{NaH}_{2} \mathrm{PO}_{4}$ solution was used as the mixing liquid, setting time of the cement containing no whiskers was 11 minutes. Setting time became longer as whisker content increased. When the cement contained 20 mass\% whiskers, the setting time was 35 minutes. Setting time was also governed by the concentration of $\mathrm{NaH}_{2} \mathrm{PO}_{4}$ solutions. As the concentration of $\mathrm{NaH}_{2} \mathrm{PO}_{4}$ solution increased, the setting time was reduced.

Fig. 2 shows the effect of whisker (aspect ratio: 6.6) content on the DTS value of the cement that was mixed with $0.6 \mathrm{~mol} / \mathrm{L} \mathrm{NaH} \mathrm{PO}_{4}$. The DTS value of the cement containing no whiskers after 24 hours was $1.5 \pm 0.3 \mathrm{MPa}$. After whiskers were added to the cement, the DTS value of the set cements increased significantly $(\mathrm{p}<0.05)$. The maximum value $(4.0 \pm$ $0.4 \mathrm{MPa}$ after 24-hour incubation) was reached when

Table 1 Relation between setting time and aragonite whisker content in calcium phosphate cement with using $0.6 \mathrm{~mol} / \mathrm{L} \mathrm{NaH}_{2} \mathrm{PO}_{4}$ solution as a mixing liquid. The cement powder containing 10 mass $\%$ whiskers, moreover, was mixed with 0.3 and 1.2 $\mathrm{mol} / \mathrm{L} \mathrm{NaH}_{2} \mathrm{PO}_{4}$ solutions

\begin{tabular}{cccc}
\hline $\begin{array}{c}\text { Cement } \\
\text { powder }\end{array}$ & $\begin{array}{c}\text { Whisker content } \\
(\text { mass\% })\end{array}$ & Mixing liquid & $\begin{array}{c}\text { Setting time } \\
\text { (minute) }\end{array}$ \\
\hline $\mathrm{A}$ & 0 & $0.6 \mathrm{~mol} / \mathrm{L} \mathrm{NaH}_{2} \mathrm{PO}_{4}$ & 11 \\
\hline \multirow{3}{*}{$\mathrm{B}$} & \multirow{2}{*}{10} & $0.3 \mathrm{~mol} / \mathrm{L} \mathrm{NaH}_{2} \mathrm{PO}_{4}$ & 25 \\
& & $0.6 \mathrm{~mol} / \mathrm{L} \mathrm{NaH}_{2} \mathrm{PO}_{4}$ & 20 \\
& & $1.2 \mathrm{~mol} / \mathrm{L} \mathrm{NaH}_{2} \mathrm{PO}_{4}$ & 18 \\
\hline $\mathrm{C}$ & 20 & $0.6 \mathrm{~mol} / \mathrm{L} \mathrm{NaH}_{2} \mathrm{PO}_{4}$ & 35 \\
\hline
\end{tabular}

30 mass \% whiskers were added. Thereafter, the DTS value decreased even with further increase of whisker content beyond 30 mass\%. The DTS value of set cement after one-week incubation was significantly higher $(\mathrm{p}<0.05)$ than the corresponding specimen incubated for 24 hours, except for cement containing no whiskers which showed no significant differences.

Fig. 3 shows the typical microstructures (SEM) of fractured surface of set cements containing 0 mass\% (A) and 20 mass\% (C) aragonite whiskers.

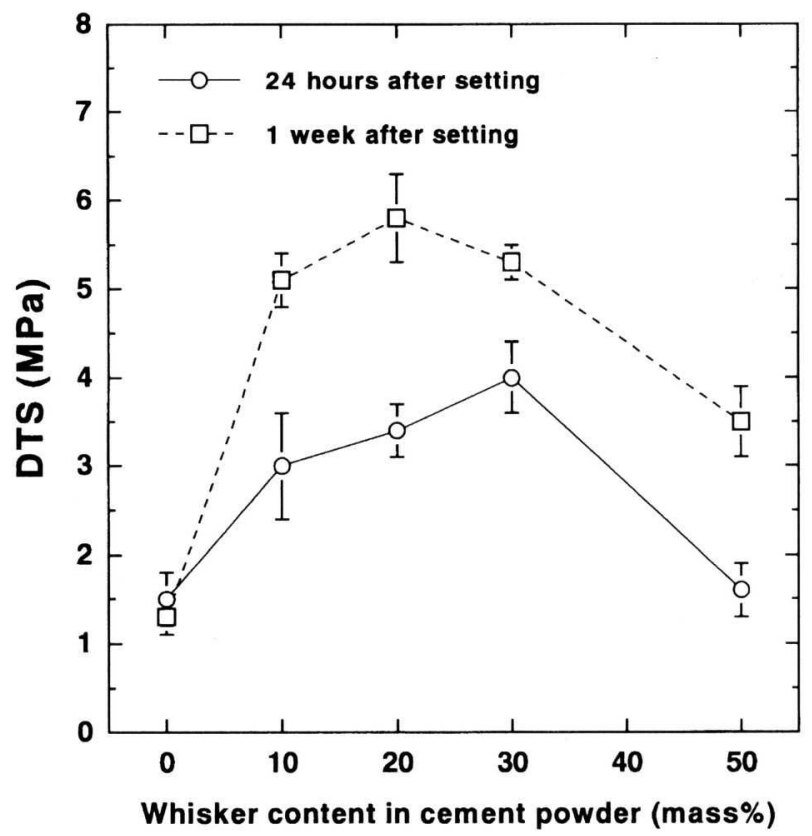

Fig. 2 Effect of adding aragonite whiskers (aspect ratio of 6.6) on the DTS of set calcium phosphate cements, at 24 hours and 1 week after setting. The cement powder was mixed with $0.6 \mathrm{~mol} / \mathrm{L} \mathrm{NaH}_{2} \mathrm{PO}_{4}$ solution.

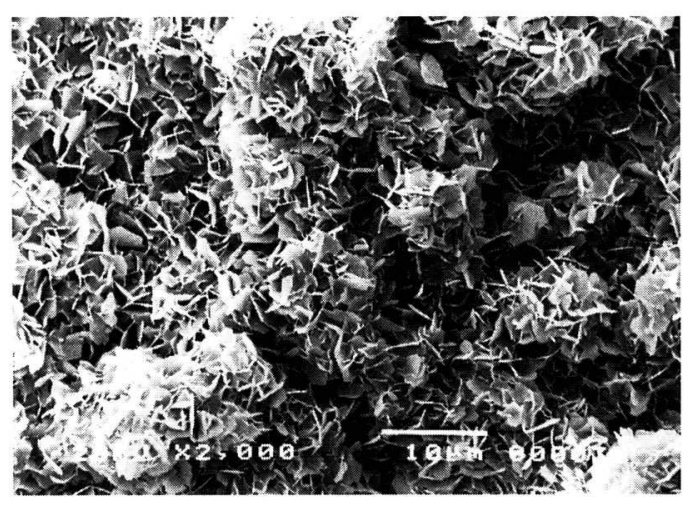

(A)
$10 \mu \mathbf{m}$

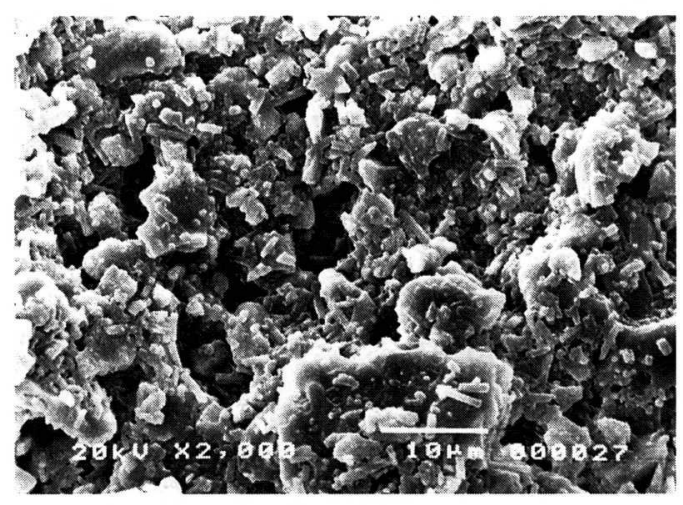

(C)

Fig. 3 Inside microstructures (SEM) of set calcium phosphate cements containing 0 mass\% (A) and 20 mass\% (C) aragonite whiskers (aspect ratio: 6.6) at 1 week after setting. The cement powder was mixed with $0.6 \mathrm{~mol} / \mathrm{L} \mathrm{NaH}_{2} \mathrm{PO}_{4}$ solution. 
Table 2 Densities of set calcium phosphate cements containing aragonite whiskers at 24 hours after setting. The cement powder was mixed with $0.6 \mathrm{~mol} /$ $\mathrm{L} \mathrm{NaH}_{2} \mathrm{PO}_{4}$ solution

\begin{tabular}{cc}
\hline Specimen: whisker content & Density: $\mathrm{g} / \mathrm{cm}^{3}$ \\
\hline A: 0 mass $\%$ & $1.41(0.04)$ \\
B: 10 mass $\%$ & $1.75(0.05)$ \\
C: 20 mass $\%$ & $1.84(0.05)$ \\
\hline$\alpha$-TCP & 2.86 \\
Hydroxyapatite & 3.16 \\
Aragonite & 2.8 \\
\hline
\end{tabular}

( ): Standard deviation

In the case of calcium phosphate cement containing no whiskers, plate-like crystals were observed. On the other hand, whiskers distributed in a dense network were observed in the set cement containing 20 mass\% whiskers (C). SEM observation thus implied that set cement with whiskers resulted in a more dense structure than that without whiskers. Density of set cements is summarized in Table 2. Densities of set cements containing 10 mass\% (B) and 20 mass\% (C) whiskers were significantly higher $(p<0.05)$ than set cement containing no whiskers (A). Table 3 summarizes the effect of aspect ratio of whiskers on the DTS of set cement containing 20 mass\% whiskers. As shown in Table 3, the aspect ratio of 6.6 for aragonite whiskers was more effective in reinforcing calcium phosphate cement than 1.0 and 20.

XRD patterns of cement powders and set cements containing 10 mass\% (B) and 20 mass\% (C) whiskers are shown in Fig. 4. It could be seen that
Table 3 Influence of aspect ratio in aragonite whiskers on the diametral tensile strength (DTS) of calcium phosphate cement containing 20 mass \% whiskers at 24 hours after setting. The cement powder was mixed with $0.6 \mathrm{~mol} / \mathrm{L} \mathrm{NaH}_{2} \mathrm{PO}_{4}$ solution

\begin{tabular}{cc}
\hline $\begin{array}{c}\text { Aspect ratio of whiskers } \\
\text { (Length/Width) }\end{array}$ & DTS, MPa \\
\hline 1.0 & $1.7(0.4)$ \\
6.6 & $3.4(0.3)$ \\
20 & $1.0(0.2)$ \\
\hline
\end{tabular}

( ): Standard deviation

the maximal peaks of $\alpha$-TCP and aragonite $\left(\mathrm{CaCO}_{3}\right)$ crystals in set cements decreased slightly and gradually with incubation time. Fig. 5 shows the FTIR spectra of set cements containing no whiskers (A) and 10 mass $\%$ whiskers (B). Set cement B containing 10 mass\% whiskers after 24-hour incubation showed distinctly the presence of the carbonate radical of aragonite whisker. However, the amount of carbonate radicals remarkably decreased at one week after setting.

\section{DISCUSSION}

Several types of whiskers or fibers are known to strengthen base materials of poor strength because of the shape and mechanical properties of whiskers and fibers. Aragonite whiskers used in this study have also been applied as a dispersing agent to strengthen plastic boards ${ }^{24)}$. On the other hand, calcium carbonate has been utilized as a raw material

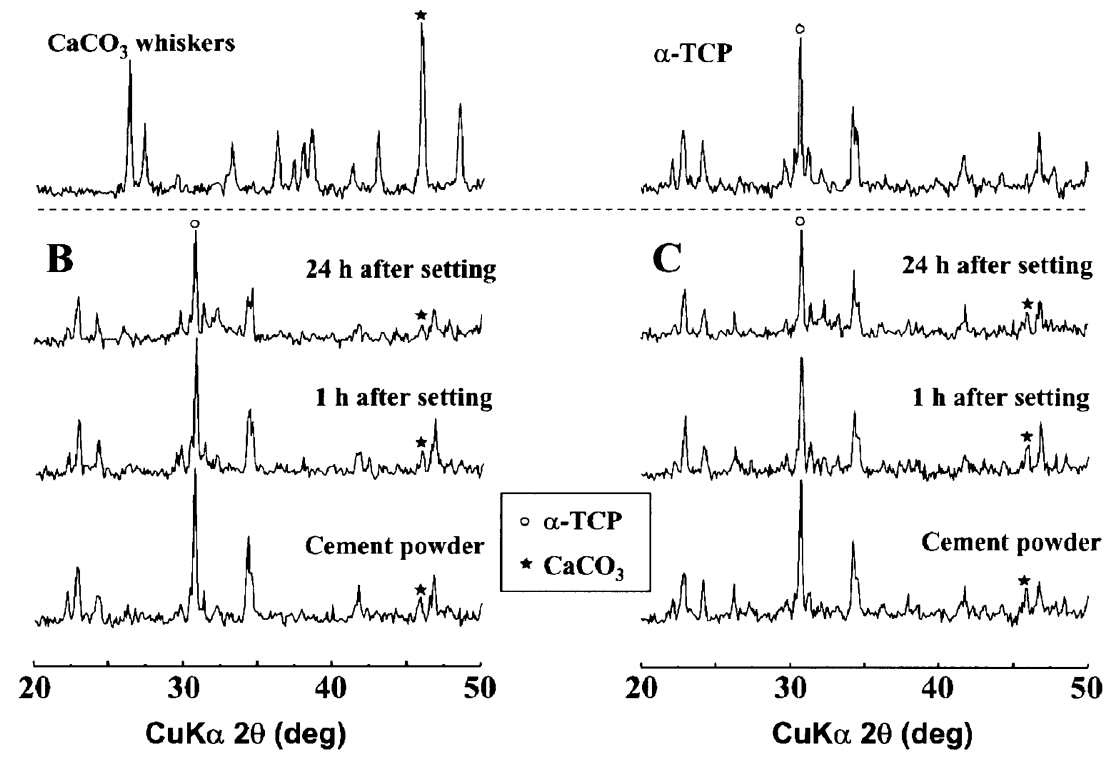

Fig. 4 X-ray diffraction patterns of $\alpha$-TCP powder, aragonite whisker, cement powders and set cements containing 10 mass\% (B) and 20 mass\% (C) whiskers (aspect ratio: 6.6). The cement powder was mixed with 0.6 $\mathrm{mol} / \mathrm{L} \mathrm{NaH}_{2} \mathrm{PO}_{4}$ solution. 
for several biomaterials. A typical example is marine coral calcium which when heated turned to calcite. Coral is treated hydrothermally in the presence of phosphate ions to form so-called porous coralline apatite (Interpore200 Irvine, CA). The porous apatite prepared from coral excels in biocompatibility, bioactivity, and bonereplacing ability - thus causing it to be widely used as a bone-filling material ${ }^{25-27)}$. It is reported that coralline apatite contains bone-like apatite, which contains a carbonate radical that plays a pivotal role in the bone-replacing function.

This experiment was set up for a two-fold purpose. First, it was to investigate if aragonite whiskers could strengthen calcium phosphate cement. Second, it was to investigate if aragonite whiskers could act as carbonated-apatite-precipitating agent in the cement.

The aragonite whiskers used in this study were able to improve the mechanical strength of calcium phosphate cement with the dispersal of particles (Fig. 2 ). This result implied that the aragonite whiskers acted as a reinforcing agent to strengthen calcium phosphate cements - such as composite materials with dispersed short glass fibers ${ }^{21)}$. One cause that brought about the strengthening effect was the shape (aspect ratio) of dispersed whiskers, since almost no dissolution of the aragonite whiskers occurred at 24 hours after setting (Fig. 5). However, whiskers of aspect ratio 20 were unable to strengthen the cement (Table 3). This could be because the strength or structure of set cement was also affected also by a condition of mixing long whiskers.

The other factor that brought about the strengthening effect was revealed by SEM observation. Set cement containing whiskers was of a denser structure than that without whiskers (Fig. 3). The presence of plate-like crystals (Fig. 3A) in the set cement containing no whiskers suggested that $\alpha$ TCP of cement powder used in this study transformed to HAP via an octacalcium phosphate (OCP) phase - because plate-like crystals originate from a typical crystal form of $\mathrm{OCP}^{15)}$. As a result, set cement containing no whiskers had a low strength with plate-like crystals. On the other hand, as shown in Fig. 3C, the set cement containing whiskers possessed a dense structure without precipitation of plate-like crystals. This might be the reason why small plate-like or needle-like crystals were precipitated by a slight dissolution of the calcium ingredient in the whiskers. The $\mathrm{Ca} / \mathrm{P}$ ratios of $\alpha$-TCP and OCP are of a lower value, 1.5 and 1.33 respectively, compared with 1.67 of HAP. Moreover, the $\alpha$-TCP cement decreased in the $\mathrm{Ca} / \mathrm{P}$ ratio after mixing with $\mathrm{NaH}_{2} \mathrm{PO}_{4}$ solution. Suzuki et al. demonstrated that a needle-like crystal of HAP was precipitated following an increase of $\mathrm{Ca} / \mathrm{P}$ ratio in the mixture ${ }^{28)}$. Therefore, the calcium element is an important factor for precipitation of needle-like HAP crystals in the cement because the relative density of set cement with needle-like crystals is higher than that with plate-like crystals (Table 2).

Fig. 6 shows the effects of calcium and carbonate ions on the structure and precipitation in set calcium phosphate cement as the aragonite whiskers dissolved. The carbonate ion formed due to the dissolution of whiskers might have contributed to the precipitation of a carbonated apatite in the cement. The precipitated HAP crystals in the cement seemed to be the most probable source of carbonate ions because the carbonate radical of cement B at one week after setting was remarkably decreased compared with that at 24 hours (Fig. 5). If this hypothesis concerning the precipitation of carbonated apatite is correct, then calcium phosphate cement containing aragonite whiskers will be more efficacious in terms
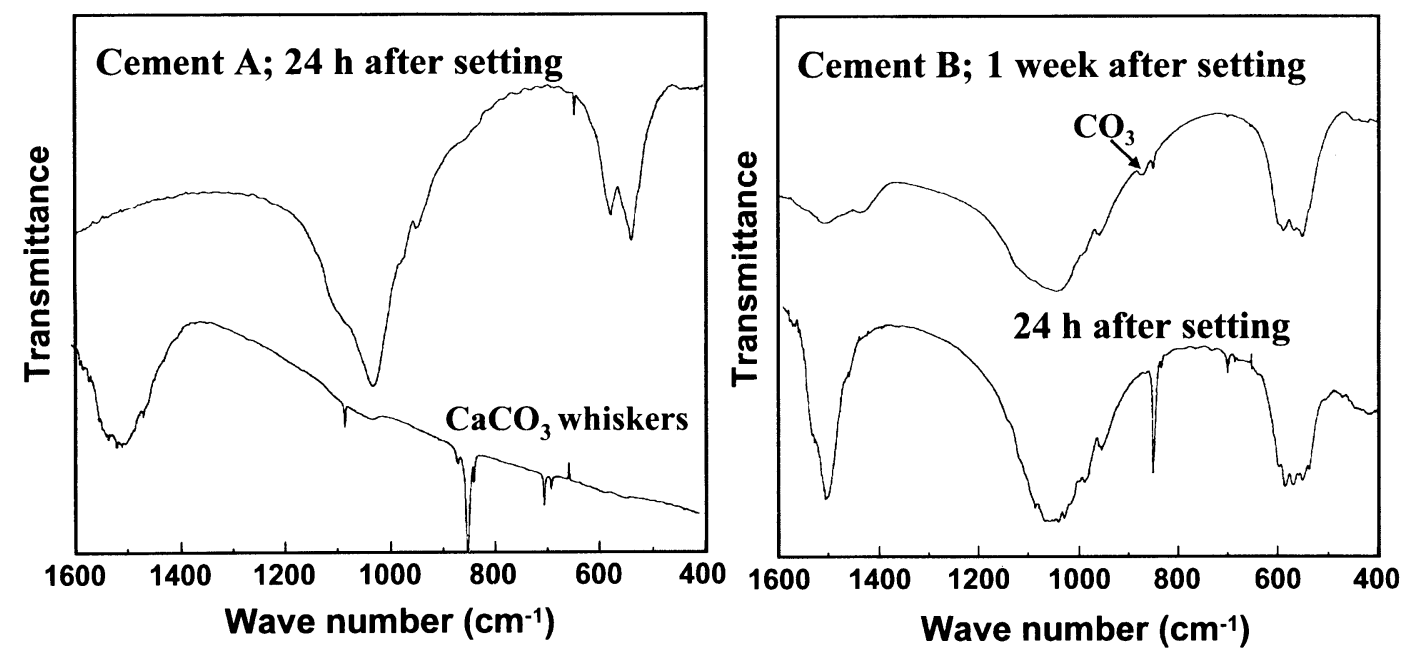

Fig. 5 FTIR spectra of set calcium phosphate cements containing 0 mass\% (A) and 10 mass\% (B) aragonite whiskers. The cement powder was mixed with $0.6 \mathrm{~mol} / \mathrm{L} \mathrm{NaH}_{2} \mathrm{PO}_{4}$ solution. 


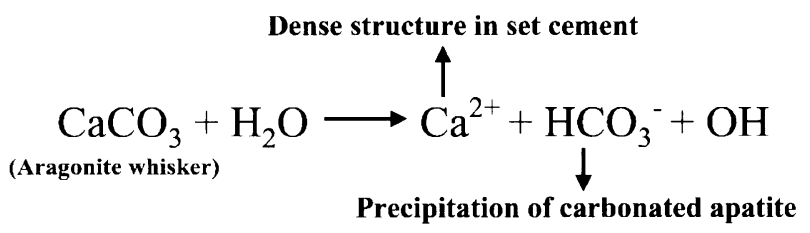

Fig. 6 Effects of calcium and carbonate ions with the dissolution of aragonite whiskers on the structure and precipitation in set calcium phosphate cement.

of biocompatibility and bioactivity than that without whiskers $^{29)}$.

This study revealed that both the particle shape (aspect ratio) and dissolution of aragonite whiskers could contribute much to improving the mechanical strength of calcium phosphate $(\alpha-\mathrm{TCP})$ cement. Moreover, it seemed that the aragonite whiskers acted as a carbonating agent for the cement. Based on the findings of this study, we could foresee the application of aragonite whiskers extending beyond calcium phosphate cement, but even to be applied in biomaterials and dental materials.

\section{ACKNOWLEDGEMENTS}

This study was supported in part by a Grant-in-aid for Scientific Research from the Ministry of Education, Science, Sports, and Culture, Japan.

\section{REFERENCES}

1) Brown W, Chow LC. Combinations of sparingly soluble calcium phosphates in slurries and paste as mineralizers and cement. US Patent, 1986, No. 4612053.

2) Ishikawa K, Takagi S, Chow LC, Ishikawa Y. Properties and mechanisms of fast-setting calcium phosphate cements. J Mater Sci: Mater Med 1995; 6: 528-533.

3) Doi Y, Takezawa Y, Shibata S, Wakamatsu N, Kamemizu H, Goto T, Iijima M, Moriwaki Y, Uno K, Kubo F, Haeuchi Y. Self-setting apatite cement. J J Dent Mater 1987; 6: 53-58.

4) Sugawara A, Fujikawa K, Takagi S, Chow LC, Nishiyama M. Histopathological and cell enzyme studies of calcium, phosphate cement. Dent Mater J 2004; 23: 613-620.

5) Monma H, Kanazawa T. The hydration of $\alpha$ tricalcium phosphate. J Ceram Soc Jpn (Yogyokyoukai-shi) 1976; 84: 209-213.

6) Yubao L, Xingdong Z, De Groot K. Hydrolysis and phase transition of alpha-tricalcium phosphate. Biomaterials 1997; 18: 737-741.

7) Durucan C, Brown PW. $\alpha$-tricalcium phosphate hydrolysis to hydroxyapatite at and near physiological temperature. J Mater Sci: Mater Med 2000; 11: 365-371.

8) Kurashina K, Kurita H, Kotani A, Takeuchi H, Hirano H. In vivo study of a calcium phosphate cement consisting of $\alpha$-tricalcium phosphate/dicalcium phosphate dibasic/tetracalcium phosphate monoxide. Biomaterials
1997; 18: 147-151

9) Yuan H, Li Y, De Bruijn JD, De Groot K, Zhang X. Tissue responses of calcium phosphate cement: A study in dogs. Biomaterials 2000; 21: 1283-1290.

10) Nagase M, Chen RB, Asada $Y$, Nakajima T. Radiographic and microscopic evaluation of subperiosteally implanted blocks of hydrated and hardened $\alpha$ tricalcium phosphate in rabbits. J Oral Maxillofac Surg 1989; 47: 582-586.

11) Kosino $\mathrm{T}$, Takahashi A, Kubota W. Bioactive cement. The Bone 1992; 6: 43-47.

12) Tanaka S, Kishi $T$, Shimogoryo R, Matsuya $S$, Ishikawa K. Biopex acquires anti-washout properties by adding sodium alginate into its liquid phase. Dent Mater J 2003; 22: 301-312.

13) Tajima S, Nishimoto N, Kishi $Y$, Matsuya S, Ishikawa K. Effects of added sodium alginate on mechanical strength of apatite cement. Dent Mater J 2004; 23: 329334.

14) Shiga $Y$, Shimogoryo R, Oka $T$, Matsuya $S$, Ishikawa $\mathrm{K}$. The effects of initial hemostatic period on the mechanical strength and transformation of apatite cement. Dent Mater J 2004; 23: 335-339.

15) Kon M, Miyamoto $Y$, Asaoka K, Ishikawa K, Lee HH. Development of calcium phosphate cement for rapid crystallization to apatite. Dent Mater J 1998; 17: 223232.

16) Kobayashi M, Takagi H, Kuroki $Y$, Niwa S, Ono M. Development and properties of glass fiber composite materials as artificial bone. Ortho Ceramic Implant 1984; 4: 79-82.

17) Kanzaki K, Kobayashi M, Mirishita M. Experimental study of the CPSA glass fiber composite materials as artificial bone (biocompatibility). J Jpn Soc Biomater 1996; 14: 55-65.

18) Imai $T$, Watari $F$, Yamagata $S$, Kobayashi $M$, Nagayama K, Toyoizumi Y, Nakamura K. Mechanical properties and estheticity of FRP orthodontic wire fabricated by hot drawing. Biomaterials 1998; 19: 21952200 .

19) Kishita C, Hamano T, Tsuru K, Nishi Y, Nagaoka E. Application of a glass fiber-reinforced composite material to clasps - The effects of immersion and repeated loading. Dent Mater J 2004; 23: 528-532.

20) Tanimoto $\mathrm{Y}$, Nemoto $\mathrm{K}$. Development of $\mathrm{Al}_{2} \mathrm{O}_{3}$ fiberreinforced $\mathrm{Al}_{2} \mathrm{O}_{3}$-based ceramics. Dent Mater J 2004; 23: 297-304

21) Kobayashi M, Kon M, Miyai K, Asaoka K. Strengthening of glass-ionomer cement by compounding short glass fibres with $\mathrm{CaO}-\mathrm{P}_{2} \mathrm{O}_{5}-\mathrm{SiO}_{2}-\mathrm{Al}_{2} \mathrm{O}_{3}$ glass. Biomaterials 2000; 21: 2051-2058.

22) Monma H. Materials sciences of calcium phosphate cement. J Jpn Sci for Biomater 1997; 15: 24-30.

23) Hirakata LM, Kon M, Asaoka K. Evaluation of apatite ceramics containing $\alpha$-tricalcium phosphate by immersion in simulated body fluid. Biomed Mater Eng 2003; 13: $247-259$.

24) Fujiwara T. Development and applied properties of calcium carbonate whiskers. Plastics Age 1995; 3: 119-123.

25) Ohgushi H, Goldberg VM, Caplan AI. Heterotopic 
osteogenesis in porous ceramics induce by marrow cells. J Orthop Res 1989; 7: 568-578.

26) Ohgushi H, Okumura $M$, Yoshikawa $T$, Inoue $K$, Senpuke N, Tamai S. Bone formation process in porous calcium carbonate and hydroxyapatite. J Biomed Mater Res 1992; 26: 885-895.

27) Manjubala I, Sivakumar M, Sampath KTS, Panduranga RK. Synthesis and characterization of functional gradient materials using Indian corals. J
Mater Sci: Mater Med 2000; 11: 705-709.

28) Suzuki S, Ohgaki M, Ichiyanaki M, Ozawa M. Preparation of needle-like hydroxyapatite. J Mater Sci Lett 1998; 17: 381-383.

29) Tieliewuhan Y, Hirata I, Sasaki A, Minagi H, Okazaki M. Osteoblast proliferation behavior and bone formation on and in $\mathrm{CO}_{3}$-apaite-collagen sponges with a porous hydroxyapatite frame. Dent Mater J 2004; 23: 258-264. 